\title{
Assessment of Factors Associated with the Quality of Life in Korean Type 2 Diabetic Patients
}

\author{
Jin Ook Chung, Dong Hyeok Cho, Dong Jin Chung and Min Young Chung
}

\begin{abstract}
Objective This study assessed factors associated with the quality of life (QoL) and investigated the influence of age in 401 Korean type 2 diabetic patients.

Methods The QoL was assessed using the latest version of the Audit of Diabetes-Dependent Quality of Life (ADDQoL) instrument in order to evaluate the perceived impact of diabetes on 19 life domains. The Beck Depression Inventory (BDI) was used to measure depressive symptoms. Logistic regression analyses were performed to assess the associations between the factors and the ADDQoL scores in the lower quartile. The interaction terms of these factors with age strata were included to evaluate the distinctive associations across age, followed by a stratified analysis.

Results According to a multivariate analysis, a positive association between depressive symptoms (BDI $\geq$ 16) and lower ADDQoL scores was consistently found across all ages. In the younger group ( $<60$ years), insulin use (odds ratio: $4.45,95 \%$ confidence interval: $1.29-15.33, \mathrm{p}=0.018$ ) and the presence of a family history of diabetes (OR: $0.23,95 \%$ CI: $0.08-0.68, p=0.008$ ) were independently associated with lower ADDQoL scores. However, in the older group ( $\geq 60$ years), insulin use and a family history of diabetes were not significantly associated with lower ADDQoL scores.

Conclusion The findings suggest that insulin use, depressive symptoms and a family history of diabetes can be associated with the QoL in Korean type 2 diabetic patients; however, the associations show different patterns of age dependency.
\end{abstract}

Key words: quality of life, Korea, type 2 diabetes mellitus

(Intern Med 52: 179-185, 2013)

(DOI: 10.2169/internalmedicine.52.7513)

\section{Introduction}

Diabetes mellitus (DM) is a chronic metabolic disorder that affects both health and quality of life (QoL). Clinical treatments tend to focus primarily on a patient's physical health, including glycemic control and diabetic complications; however, these treatments may be inadequate in managing the full burden of diabetes (1). The QoL of DM patients is increasingly recognized as an important health outcome, and it is important to identify risk factors for lower diabetes-related QoL in order to manage these risk factors properly and improve QoL in diabetic patients $(2,3)$. Various instruments assessing the QoL related to diabetes have been used in patients with type $2 \mathrm{DM}$. While generic health- related QoL measures have been widely used to assess diabetes-related QoL, diabetes-specific measures are preferable in diabetic patients (4). Among diabetes-specific QoL measures, the Audit of Diabetes Dependent Quality of Life (ADDQoL) is a widely-used instrument of diabetes-specific QoL that assesses an individual's perceptions of the impact of diabetes on their QoL (5).

Many factors have been suggested to impact QoL in type 2 DM patients. Strict glycemic control of diabetes is required to prevent chronic diabetic complications. However, the complexity of treatment regimens required to achieve strict glycemic control may influence an individual's QoL (6). The presence of chronic diabetic complications has been reported to have a significant influence on the QoL $(7,8)$. However, the QoL is a subjective concept that 
includes multidimensional factors such as physical health, functioning, well-being and psychological factors. In addition, because variations exist according to ethnic and cultural backgrounds, different studies of factors influencing the QoL in patients with type 2 DM are required for different populations (9).

Age has been included as a significant covariate in previous studies investigating the determining factors of the QoL in type 2 diabetic patients $(10,11)$; however, the possible interaction of age has not been considered. The purpose of this study was to assess factors associated with the diabetesrelated QoL measured by the ADDQoL and to investigate the influence of age in Koreans with type 2 DM.

\section{Materials and Methods}

\section{Subjects}

This study was conducted from November 2010 to October 2011 and was approved by the local ethics committee. All participants gave their informed consent. A total of 401 patients with type $2 \mathrm{DM}$ who visited the diabetes outpatient clinic of our hospital were investigated. The sample size was estimated based on the criteria that five to ten subjects per item were required for the psychometric assessment of an instrument (12). For the 19-item ADDQoL, a sample of at least 190 subjects would be required. The study subjects were selected using a random number table. Patients having any of the following characteristics were excluded from the study: glucocorticoid use, active liver disease, end-stage renal disease, malignancy, an acute coronary or cerebrovascular event and a cognitive or physical condition to preclude participation. History and physical examinations, including measurements of blood pressure, height and body weight, were conducted. Body mass index (BMI) was calculated as weight $(\mathrm{kg})$ divided by the square of height $\left(\mathrm{m}^{2}\right)$. Hypertension was diagnosed if the patient had a blood pressure greater than $140 / 90 \mathrm{mmHg}$ or used antihypertensive drugs. Smoking was defined as never/past or current.

Marital status, educational background, occupation, familial history of diabetes in first-degree relatives and the duration of diabetes were investigated. The level of exercise was also obtained from each patient: no exercise, $\leq 2$ days per week of sporting activity lasting at least 30 minutes per day and $\geq 3$ days per week of sporting activity lasting at least 30 minutes per day. The diabetic patients were divided into two groups based on treatment mode: an insulin use group and a non-insulin use group. The insulin use group included patients treated with a combination of insulin and oral hypoglycemic agents, as well as those treated with insulin only. The frequency of daily insulin injections was also investigated.

\section{Measures}

Depressive symptoms were assessed with the Beck Depression Inventory (BDI), which consists of 21 items related to cognitive and somatic symptoms of depression (13). Depression was defined as a BDI score $\geq 16$. The overall BDI measure yielded good internal consistency (Cronbach's $\alpha=$ $0.91)$.

The QoL was assessed with the ADDQoL instrument (5). The latest version of the ADDQoL assesses the perceived impact of diabetes on 19 life domains (9). The ADDQoL questionnaire begins with two overview items assessing the patient's present global QoL (range +3 to -3 ) and the impact of diabetes on the QoL (range -3 to +1 ). For both items, lower scores indicate a poorer QoL. In the subsequent items, the respondent rates the impact of diabetes (range -3 to +1 ) on 19 item domains and the importance (range 3 to 0 ) of each domain for their QoL. The 19 life domains are as follows: leisure activities, working life, local or long-distance journeys, holidays, physical health, family life, friendships and social life, close personal relationships, sex life, physical appearance, self-confidence, motivation to achieve things, people's reactions, feelings about the future, financial situation, living conditions, dependence on others, freedom to eat and freedom to drink. The impact scores are multiplied by the importance rating to produce a weighted impact score for each domain, resulting in scores ranging from -9 to +3 . The weighted impact scores for the domains are divided by the number of applicable domains to yield an average weighted impact (AWI) score (range -9 to +3 ), where more negative scores reflect a worse QoL and a more negative impact of diabetes on the QoL. The overall reliability coefficient (Cronbach's $\alpha$ ) of the ADDQoL is 0.96, thus indicating a good internal consistency.

The levels of glycated hemoglobin (HbA1C) were measured using ion exchange liquid chromatography and a model HLC-723-GHbV apparatus (Tosoh, Tokyo, Japan). The levels of urinary albumin excretion were determined using the urinary albumin:creatinine $(\mathrm{Cr})$ ratio $(\mathrm{UAE})$ in random urine samples. The urinary albumin concentrations were measured using the immunoturbidimetric method with a commercial kit (Randox, Antrim, UK). The estimated glomerular filtration rates (eGFRs) were calculated using the equation from the Modification of Diet in Renal Disease study (MDRD) (14). Nephropathy was defined as UAE $\geq 300 \mathrm{mg} /$ $\mathrm{gCr}$ or eGFR $<60 \mathrm{~mL} / \mathrm{min}$ per $1.73 \mathrm{~m}^{2}$. To evaluate retinopathy, an ophthalmologist performed fundoscopy after pupillary dilation. Peripheral neuropathy was scored based on clinical examinations (Achilles tendon reflexes, vibration sensation determined with a $128 \mathrm{~Hz}$ vibration fork at the hallux and sensory perception determined with a 10-g Semmes-Weinstein monofilament) and neuropathy symptom scores. The clinical examination and neuropathy symptom scores ranged from 0-10 and 0-9, respectively. Peripheral neuropathy was defined as moderate signs (score $\geq 6$ ) with or without symptoms or mild signs (score 3-5) with moderate symptoms (score $\geq 5$ ) (15).

\section{Statistical analyses}

The data were expressed as the mean \pm standard devia- 
Table 1. Demographic and Clinical Characteristics of the Study Population

\begin{tabular}{|c|c|c|c|c|}
\hline Variables & & N (\%) & AWI score & p value \\
\hline Number (n) & & 401 & $-2.73(-4.16,-1.57)$ & \\
\hline Age (years) & $\begin{array}{l}\geq 60 \\
<60\end{array}$ & $\begin{array}{l}222(55.4) \\
179(44.6)\end{array}$ & $\begin{array}{l}-2.62(-3.88,-1.37) \\
-3.17(-4.61,-1.76)\end{array}$ & 0.079 \\
\hline Gender & $\begin{array}{l}\text { Male } \\
\text { Female }\end{array}$ & $\begin{array}{l}220(54.9) \\
181(45.1)\end{array}$ & $\begin{array}{l}-2.73(-4.11,-1.59) \\
-2.73(-4.29,-1.43)\end{array}$ & 0.863 \\
\hline Education & $\begin{array}{l}\text { High school or more } \\
\text { Middle school or less }\end{array}$ & $\begin{array}{l}174(43.4) \\
227(56.6)\end{array}$ & $\begin{array}{l}-2.68(-4.21,-1.57) \\
-2.94(-4.16,-1.66)\end{array}$ & 0.693 \\
\hline Employment & $\begin{array}{l}\text { Full or part time } \\
\text { None }\end{array}$ & $\begin{array}{l}151(37.7) \\
250(62.3)\end{array}$ & $\begin{array}{l}-2.84(-4.34,-1.76) \\
-2.77(-4.11,-1.64)\end{array}$ & 0.585 \\
\hline Family history of diabetes & $\begin{array}{l}\text { Yes } \\
\text { No }\end{array}$ & $\begin{array}{l}209(52.1) \\
192(47.9)\end{array}$ & $\begin{array}{l}-2.63(-4.00,-1.16) \\
-3.01(-4.54,-1.73)\end{array}$ & 0.025 \\
\hline Marital status & $\begin{array}{l}\text { Married } \\
\text { Unmarried and not living as } \\
\text { married }\end{array}$ & $\begin{array}{l}248(61.8) \\
153(38.2)\end{array}$ & $\begin{array}{l}-2.71(-4.11,-1.61) \\
-3.55(-4.72,-2.00)\end{array}$ & 0.082 \\
\hline Smoking & $\begin{array}{l}\text { Current or ex-smoker } \\
\text { None }\end{array}$ & $\begin{array}{l}141(35.2) \\
260(64.8)\end{array}$ & $\begin{array}{l}-2.86(-4.21,-1.54) \\
-2.61(-3.97,-1.66)\end{array}$ & 0.612 \\
\hline Hypertension & $\begin{array}{l}\text { Yes } \\
\text { No }\end{array}$ & $\begin{array}{l}222(55.4) \\
179(44.6)\end{array}$ & $\begin{array}{l}-2.58(-4.10,-1.56) \\
-2.93(-4.35,-1.78)\end{array}$ & 0.297 \\
\hline Diabetes duration & $\begin{array}{l}\geq 5 \text { years } \\
<5 \text { years }\end{array}$ & $\begin{array}{l}229(57.1) \\
172(42.9)\end{array}$ & $\begin{array}{l}-2.93(-4.21,-1.86) \\
-2.52(-4.03,-1.04)\end{array}$ & 0.039 \\
\hline BMI & $\begin{array}{l}<25 \mathrm{~kg} / \mathrm{m}^{2} \\
\geq 25 \mathrm{~kg} / \mathrm{m}^{2}\end{array}$ & $\begin{array}{l}242(60.3) \\
159(39.7)\end{array}$ & $\begin{array}{l}-2.93(-4.15,-1.82) \\
-2.47(-4.25,-1.20)\end{array}$ & 0.083 \\
\hline Exercise & $\begin{array}{l}\text { none } \\
\leq 2 \text { per week } \\
\geq 3 \text { per week }\end{array}$ & $\begin{array}{l}105(26.2) \\
65(16.2) \\
231(57.6)\end{array}$ & $\begin{array}{l}-2.58(-4.10,-1.33) \\
-2.88(-4.31,-1.61) \\
-2.73(-4.26,-1.64)\end{array}$ & 0.671 \\
\hline $\mathrm{HbA} 1 \mathrm{C}$ & $\begin{array}{l}\geq 7 \% \\
<7 \%\end{array}$ & $\begin{array}{l}295(73.6) \\
106(26.4)\end{array}$ & $\begin{array}{l}-2.94(-4.32,-1.68) \\
-2.15(-3.91,-1.02)\end{array}$ & 0.033 \\
\hline Treatment & $\begin{array}{l}\text { Insulin use } \\
\text { Non-insulin use }\end{array}$ & $\begin{array}{l}86(21.4) \\
315(78.6)\end{array}$ & $\begin{array}{l}-3.52(-4.50,-2.25) \\
-2.53(-4.00,-1.36)\end{array}$ & 0.008 \\
\hline $\begin{array}{l}\text { Method of insulin } \\
\text { treatment }\end{array}$ & $\begin{array}{l}\text { None } \\
\text { BI } \\
\text { Basal-plus } \\
\text { Basal-bolus } \\
\text { Premixed insulin-based }\end{array}$ & $\begin{array}{l}315(78.6) \\
35(8.7) \\
9(2.2) \\
16(4.0) \\
26(6.5)\end{array}$ & $\begin{array}{l}-2.53(-4.00,-1.36) \\
-3.21(-4.60,-2.12) \\
-3.47(-4.35,-1.69) \\
-3.93(-4.88,-2.72) \\
-3.57(-4.46,-1.91)\end{array}$ & 0.104 \\
\hline $\begin{array}{l}\text { Frequency of insulin } \\
\text { Injection }\end{array}$ & $\begin{array}{l}\text { None } \\
\text { One } \\
\text { Two } \\
\text { Three or more }\end{array}$ & $\begin{array}{l}315(78.6) \\
42(10.5) \\
26(6.5) \\
18(4.5)\end{array}$ & $\begin{array}{l}-2.53(-4.00,-1.36) \\
-3.17(-4.48,-2.12) \\
-3.90(-4.41,-1.78) \\
-3.75(-4.77,-2.65)\end{array}$ & 0.055 \\
\hline $\begin{array}{l}\text { Microvascular } \\
\text { complications }\end{array}$ & $\begin{array}{l}\text { None } \\
\text { One } \\
\text { Two or more }\end{array}$ & $\begin{array}{l}128(31.9) \\
145(36.2) \\
128(31.9)\end{array}$ & $\begin{array}{l}-2.20(-3.86,-1.15) \\
-3.22(-4.32,-1.87) \\
-3.63(-4.58,-1.88)\end{array}$ & 0.007 \\
\hline $\mathrm{BDI} \geq 16$ & $\begin{array}{l}\text { Yes } \\
\text { No }\end{array}$ & $\begin{array}{l}118(29.4) \\
283(70.6) \\
\end{array}$ & $\begin{array}{l}-3.65(-4.69,-2.27) \\
-2.43(-3.87,-1.32) \\
\end{array}$ & $<0.001$ \\
\hline
\end{tabular}

The values are given as the median (interquartile range). The numbers in parenthesis are percentages. AWI score: average weighted impact score, BMI: body mass index, BI: basal insulin with or without a second injection of basal insulin, HbA1C: glycated hemoglobin, BDI: Beck Depression Inventory

tion, median (interquartile range) or frequency distribution, unless otherwise stated. The $\chi^{2}$ test was used to determine significance, if any, in the differences measured between groups for each variable. The prevalence odds ratio (OR) for an ADDQoL score in the lower quartile of the distribution was estimated using a multivariate logistic regression analysis with adjustment for gender and the identified independent variables. The interaction terms of the relevant factors with age strata ( $<60$-years-of-age vs. $\geq 60$-years-of-age) were included to evaluate the distinctive associations across age. If a significant interaction was detected, a stratified analysis was further conducted to compare the OR according to the age strata. The results were corrected for multiple compari- sons. The statistical analyses were performed using SPSS version 17.0 software (SPSS, Chicago, IL USA). A p-value $<0.05$ was considered statistically significant.

\section{Results}

The clinical characteristics of the enrolled type 2 diabetic patients are shown in Table 1 . The mean age of the subjects was $59.2 \pm 11.5$ years. Diabetes duration and the HbA1C levels were $8.8 \pm 8.3$ years and $8.4 \pm 2.2 \%$, respectively. The treatment methods for diabetes were: lifestyle modification alone $(\mathrm{n}=21,5.2 \%)$, oral hypoglycemic agents alone $(294,73.3 \%)$ or insulin-based therapy $(86,21.4 \%)$. The 
Table 2. Audit of Diabetes-dependent Quality of Life (ADDQoL) Weighted Impact Scores for Each Life Domain

\begin{tabular}{|c|c|c|c|}
\hline Domain & $\begin{array}{c}\text { Unweighted impact } \\
\text { scores }\end{array}$ & Importance rating & $\begin{array}{l}\text { Weighted impact } \\
\text { score }\end{array}$ \\
\hline Leisure activities & $-1.0(-2.0,-1.0)$ & $2.0(1.0,2.0)$ & $-2.0(-4.0,0)$ \\
\hline Working life & $-2.0(-2.0,-1.0)$ & $2.0(2.0,3.0)$ & $-3.0(-6.0,-1.0)$ \\
\hline Local or long-distance journey & $-2.0(-2.0,-0.5)$ & $2.0(1.0,2.0)$ & $-2.0(-4.0,0)$ \\
\hline Holidays & $-1.5(-2.0,0)$ & $2.0(1.0,2.0)$ & $-2.0(-4.0,0)$ \\
\hline Physical health & $-1.0(-2.0,0)$ & $2.0(1.0,2.0)$ & $-2.0(-4.0,0)$ \\
\hline Family life & $-2.0(-2.0,-1.0)$ & $2.0(2.0,3.0)$ & $-3.0(-6.0,-1.0)$ \\
\hline Friendship and social life & $-2.0(-2.0,0)$ & $2.0(2.0,2.0)$ & $-2.0(-4.0,0)$ \\
\hline Close personal relationship & $-1.0(-2.0,0)$ & $2.0(2.0,3.0)$ & $-2.0(-4.0,0)$ \\
\hline Sex life & $-1.0(-2.0,-1.0)$ & $2.0(1.0,2.0)$ & $-2.0(-4.0,0)$ \\
\hline Physical appearance & $-1.0(-2.0,0)$ & $2.0(1.0,2.0)$ & $-2.0(-4.0,0)$ \\
\hline Self-confidence & $-2.0(-2.0,-1.0)$ & $2.0(2.0,3.0)$ & $-4.0(-6.0,-1.0)$ \\
\hline Motivation to achieve things & $-2.0(-2.0,-1.0)$ & $2.0(2.0,3.0)$ & $-4.0(-6.0,-2.0)$ \\
\hline People's reaction & $-1.0(-2.0,0)$ & $2.0(1.0,2.0)$ & $-1.0(-4.0,0)$ \\
\hline Feelings about the future & $-2.0(-2.0,-1.0)$ & $2.0(2.0,2.0)$ & $-4.0(-4.0,-1.0)$ \\
\hline Financial situation & $-1.0(-2.0,0)$ & $2.0(2.0,3.0)$ & $-2.0(-4.0,0)$ \\
\hline Living conditions & $-1.0(-2.0,-1.0)$ & $2.0(2.0,2.0)$ & $-2.0(-4.0,-1.0)$ \\
\hline Dependence on others & $-1.0(-2.0,0)$ & $2.0(1.0,2.0)$ & $-1.0(-4.0,0)$ \\
\hline Freedom to eat & $-2.0(-3.0,-1.0)$ & $2.0(2.0,3.0)$ & $-4.0(-6.0,-2.0)$ \\
\hline Freedom to drink & $-2.0(-3.0,-1.0)$ & $2.0(1.0,3.0)$ & $-4.0(-6.0,-1.0)$ \\
\hline
\end{tabular}

The values are given as the median (interquartile range).

methods of insulin treatment $(\mathrm{n}=86)$ were: basal insulin $(\mathrm{BI})$ with or without a second injection of BI $(n=35,40.7 \%)$, basal-plus $(9,10.5 \%)$, basal-bolus $(16,18.6 \%)$ or premixed insulin-based therapy (1-3/day) $(26,30.2 \%)$. Three of the subjects were taking antidepressant medication and they were scored as depressed (BDI $\geq 16$ ) despite the medication. The median weighted impact ADDQoL score was -2.73, indicating an overall negative impact of diabetes on the QoL. The most negatively impacted domains in the ADDQoL instrument were self-confidence, motivation to achieve things, feelings about the future, freedom to eat and freedom to drink (Table 2). The diabetes-related QoL was marginally better in older, married and obese patients and was significantly higher in the patients with a family history of diabetes (Table 1). The diabetes-related QoL was significantly lower in the patients on insulin, those with higher HbA1C levels, those with longer durations of diabetes, those with one or more diabetes-related complications and those with depressive symptoms. The frequency of insulin injection was marginally inversely associated with the diabetes-related QoL.

Table 3 shows the results of the logistic regression analysis of the ADDQoL scores in the lower quartile. In the univariate analysis, the $\mathrm{HbA1C}$ levels, insulin use, microvascular complications and depression were significantly associated with lower ADDQoL scores, whereas older age and a family history of diabetes were associated with higher diabetes-related QoL scores (model 1). However, gender, education, employment, marital status, smoking status, hypertension, diabetes duration, obesity and exercise status were not significantly associated with lower ADDQoL scores. According to multivariate analyses, older age and the presence of a family history of diabetes were significantly associated with higher diabetes-related QoL scores, whereas depressive symptoms were associated with lower ADDQoL scores (model 2). When the interaction term between a family history of diabetes and age was added to model 2 (model 3 ), the association between a family history of diabetes and the ADDQoL score was found to be statistically significant $(p=0.004)$ and the interaction term was statistically significant $(\mathrm{p}=0.032)$. When the interaction term between insulin use and age was added to model 2 (model 4), the association between insulin use and the ADDQoL score became statistically significant $(\mathrm{p}=0.043)$ and the interaction term was statistically significant $(\mathrm{p}=0.042)$. However, when the interaction term between depressive symptoms and age was added to model 2 (model 5), the interaction term was not statistically significant $(\mathrm{p}=0.518)$. These findings indicate that there is a positive association between depressive symptoms and lower ADDQoL scores regardless of age, although age might modify the relationship between a family history of diabetes and lower ADDQoL scores and that between insulin use and lower ADDQoL scores.

To further examine the interactions between a family history of diabetes and age as well as those between insulin use and age, we calculated the adjusted $O R$ for the ADDQoL scores in the lower quartile according to the presence of insulin use and a familial history of diabetes by age group. The patients with a family history of diabetes were associated with a low OR for lower ADDQoL scores com- 


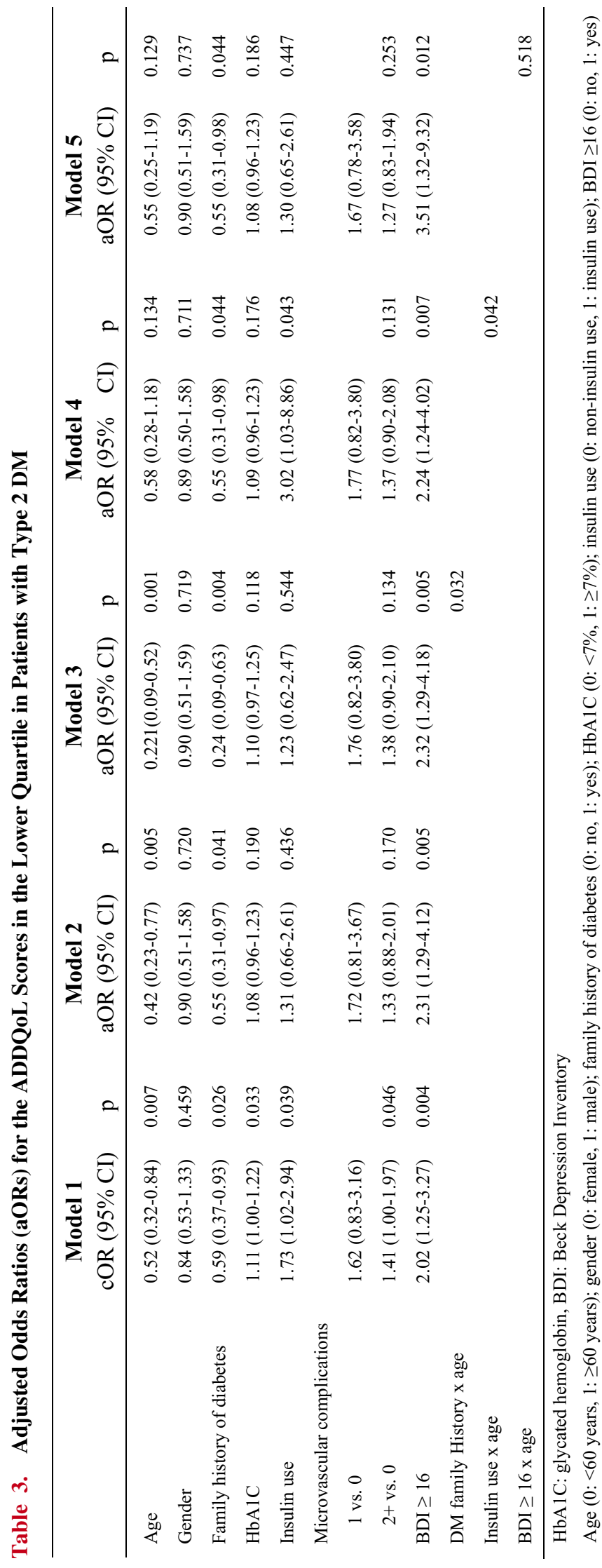

pared with those without a family history of diabetes in the younger group $(<60$ years; OR: $0.23,95 \%$ confidence interval (CI): $0.08-0.68, \mathrm{p}=0.008$ ). Insulin use was independently associated with lower ADDQoL scores in the younger group (<60 years) (OR: 4.45, 95\% CI: 1.29-15.33, p=0.018). On the other hand, insulin use and a family history of diabetes were not significantly associated with lower ADDQoL scores in the older group ( $\geq 60$ years) (OR: $1.07,95 \% \mathrm{CI}$ : $0.55-2.10, \mathrm{p}=0.824$ and OR: $0.58,95 \% \mathrm{CI}: 0.24-1.39, \mathrm{p}=$ 0.229 , respectively).

As depression is one of the most prevalent diabetic complications and factors related to depression might also be prevalent in type 2 diabetic patients (16), we further investigated the factors associated with lower ADDQoL scores in the subjects without depressive symptoms. In the univariate analysis, age, the HbA1C levels, insulin use and a family history of diabetes were significantly associated with lower ADDQoL scores (Table 4). In the multivariate analysis, age and a family history of diabetes remained significant determinants of lower ADDQoL scores. Two interactions were also statistically significant: age with a family history of diabetes $(p=0.024)$ and age with insulin use $(p=0.039)$. These results indicate that age dependency in the relationship between a family history of diabetes and lower ADDQoL scores, and that between insulin use and lower ADDQoL scores is also retained in type 2 diabetic patients without depressive symptoms.

\section{Discussion}

In this study, Korean patients with type 2 DM had low perceptions of the QoL related to diabetes. Depressive symptoms showed a negative association with the diabetesrelated QoL across all ages; however, insulin use and a family history of diabetes showed different associations with the ADDQoL scores based on age group. There was an inverse association between a family history of diabetes and lower ADDQoL scores and a positive association between insulin use and lower ADDQoL scores in the younger group $(<60$ years), while there were no significant relationships in the older group ( $\geq 60$ years). In addition, the relationships of a family history of diabetes, insulin use and age to lower ADDQoL scores were retained in the type 2 diabetic patients without depressive symptoms.

$\mathrm{DM}$ is a disorder that requires self-management and lifetime metabolic control to improve the QoL. Therefore, one of the major objectives in the management of type $2 \mathrm{DM}$ is to minimize a deterioration in the QoL due to diabetes. Depression is a frequent comorbidity of type 2 DM. Depression in diabetic patients may be associated with negative impacts on compliance with diet, exercise and medications (17). In addition, previous studies have reported that depressive symptoms are associated with lower perceptions of the QoL in patients with type $2 \mathrm{DM}(10,18)$. Lemon et al. (18) reported that ADDQoL scores are inversely associated with depressive symptoms assessed by the Centers for Epidemiologic Studies Depression (CES-D) Scale. Sundaram et al. (10) also reported that depressive symptoms were associated with lower ADDQoL scores in a multivariate analysis. Our results regarding depression are consistent with the results of these previous studies. In the present study, nearly 
Table 4. Odds Ratios (ORs) for the ADDQoL Scores in the Lower Quartile in Patients with Type 2 DM without Depressive Symptoms

\begin{tabular}{|c|c|c|c|c|}
\hline & $\operatorname{cOR}(95 \% \mathrm{CI})$ & $\mathrm{p}$ & $\mathrm{aOR}(95 \% \mathrm{CI})$ & $\mathrm{p}$ \\
\hline Age & $0.53(0.28-0.99)$ & 0.041 & $0.40(0.17-0.98)$ & 0.024 \\
\hline Gender & $0.79(0.43-1.46)$ & 0.465 & $0.64(0.30-1.37)$ & 0.256 \\
\hline Family history of diabetes & $0.51(0.28-0.92)$ & 0.027 & $0.33(0.15-0.72)$ & 0.005 \\
\hline $\mathrm{HbA} 1 \mathrm{C}$ & $1.21(1.07-1.38)$ & 0.030 & $1.16(0.99-1.36)$ & 0.063 \\
\hline Insulin use & $2.17(1.06-4.43)$ & 0.032 & $2.26(0.91-5.60)$ & 0.078 \\
\hline Microvascular complications & $1.13(0.74-1.73)$ & 0.569 & $1.10(0.67-1.79)$ & 0.694 \\
\hline
\end{tabular}

$30 \%$ of the respondents exhibited depressive symptoms (BDI score $\geq 16$ ). The presence of depressive symptoms in patients with type 2 DM was found to be significantly associated with lower ADDQoL scores in the multivariate analysis. In addition, our findings indicate that this negative association is consistent across all ages. The close relationship between the presence of depressive symptoms and lower diabetes-related QoL scores suggests that more intensive psychological support is required for type 2 diabetic patients throughout life.

Recently, Collins et al. (19) showed that older age ( $\geq 60$ years of age) might be associated with higher diabetesrelated QoL scores, although this statistically significant association was diminished after adjusting for relevant factors. Sundaram et al. (10) also reported that older age ( $\geq 60$ years of age) was independently associated with higher ADDQoL scores in a multivariate analysis. Kong et al. (11) reported that there was a significant influence of age on ADDQoL score in Chinese type 2 diabetic patients and that the ADDQoL scores of the patients with lower education levels were significantly lower than those of patients with higher education levels among patients $<50$ years of age, while no significant differences were observed in patients $\geq 50$ years of age. In the present study, the patients with a family history of diabetes reported significantly higher ADDQoL scores than those without a family history of diabetes. In addition, in our study, the relationship between a history of familial diabetes adjusted by age interaction terms for lower ADDQoL scores was statistically significant. The presence of a family history of diabetes was significantly associated with a low OR for lower ADDQoL scores in the younger patients, but not in the older patients. A family history of type $2 \mathrm{DM}$ is associated with an increased risk of developing the disease (20). Recently, it was suggested that a close relationship may exist between a family history of diabetes and QoL in individuals with diabetes. Akinci et al. (21) reported that, in Turkish type 2 diabetic patients, the perception degrees of the "impact" and "diabetes-related worry" aspects of QoL measured by the diabetes-specific quality of life (DQoL) assessment tool were better in patients with a family history of diabetes than those in patients without a family history, while the total DQoL scales were lower in patients with a family history of diabetes. Therefore, a family history of diabetes may influence diabetes-related QoL as well as the development of diabetes. Social support has positive effects on psychological health, physical well-being and QoL. Familial support may be particularly important in diabetes management, where family members are involved in many aspects of the required health-care activities of diabetic patients (22). Our results suggest that the presence of a diabetic patient as a family member may counteract the negative impacts of the perception of the degree of QoL in younger Koreans with type $2 \mathrm{DM}$. This may be related to pre-information about diabetes or inter-relationships between family members with diabetes. However, because factors affecting the perception of QoL may differ according to ethnicity and cultural background, it is not certain that this relationship is a universal finding in the diabetic population around the world.

Type $2 \mathrm{DM}$ is characterized by defective insulin secretion and insulin resistance. The defects in insulin secretion may be progressive. The UK Prospective Diabetes Study demonstrated that patients with type $2 \mathrm{DM}$ have less than $50 \%$ of the normal level of insulin secretion at diagnosis and less than $25 \%$ of the normal level of insulin secretion six years after diagnosis (23). This decline in $\beta$-cell function may require insulin therapy to achieve good glycemic control in type 2 diabetics. However, insulin therapy may affect the QoL in diabetic patients. Bashoff and Beaser (24) showed that patients with type $2 \mathrm{DM}$ might be resistant to insulin injections because they do not physically depend on insulin for survival. Bradley et al. (5) reported a greater negative impact of diabetes on the QoL in insulin-treated patients. Collins et al. (19) reported an inverse association between insulin use and higher ADDQoL scores adjusted for age and sex; however, there was no longer a significant association after further adjustment for other variables, including education, marital status, diabetes complications and diabetes care models. Our results also showed that insulin-treated patients have lower ADDQoL scores than noninsulin-treated patients. More frequent insulin injections were marginally associated with a lower diabetes-related QoL. In addition, when interaction terms with age strata were included, the association between insulin use and lower ADDQoL scores was found 
to be age-dependent (model 4), and insulin use was independently associated with lower ADDQoL scores in the younger groups. The interaction with age strata was also statistically significant in the subjects without depressive symptoms. Therefore, our results suggest that the impact of insulin use on the QoL in type 2 DM patients differs depending on age.

This study is associated some limitations. First, as our study was conducted in one outpatient clinic, the results might not be representative of other diabetes patients in Korea. Second, as the design of our study was cross-sectional, the causative nature of the associations cannot be established. Despite these limitations, our findings might provide important information regarding the determinants of the QoL and the patterns of age dependency in type 2 diabetic patients.

In conclusion, our results show that insulin use, depressive symptoms and a family history of diabetes are associated with the QoL in Korean type 2 diabetic patients, although these associations show different patterns of age dependency. These findings suggest that we may need different approaches based on age group for dealing with the QoL in type 2 diabetic patients. Further prospective studies are needed to confirm these associations.

The authors state that they have no Conflict of Interest (COI).

\section{References}

1. Kaplan RM. The significance of quality of life in health care. Qual Life Res 12: S3-S16, 2003.

2. Anderson RM, Fitzgerald JT, Wisdom K, Davis WK, Hiss RG. A comparison of global versus disease-specific quality-of-life measures in patients with NIDDM. Diabetes Care 20: 299-305, 1997.

3. Testa MA, Simonson DC, Turner RR. Valuing quality of life and improvements in glycemic control in people with type 2 diabetes. Diabetes Care 21: C44-C52, 1998.

4. Speight J, Reaney MD, Barnard KD. Not all roads lead to Rome-a review of quality of life measurement in adults with diabetes. Diabet Med 26: 315-327, 2009.

5. Bradley C, Todd C, Gorton T, Symonds E, Martin A, Plowright R. The development of an individualized questionnaire measure of perceived impact of diabetes on quality of life: the ADDQoL. Qual Life Res 8: 79-91, 1999.

6. Weinberger M, Kirkman MS, Samsa GP, et al. The relationship between glycemic control and health-related quality of life in patients with non-insulin-dependent diabetes mellitus. Med Care 32: 1173-1181, 1994

7. Glasgow RE, Ruggiero L, Eakin EG, Dryfoos J, Chobanian L.
Quality of life and associated characteristics in a large national sample of adults with diabetes. Diabetes Care 20: 562-567, 1997.

8. Brown GC, Brown MM, Sharma S, Brown H, Gozum M, Denton P. Quality of life associated with diabetes mellitus in an adult population. J Diabetes Complications 14: 18-24, 2000.

9. Wee HL, Tan CE, Goh SY, Li SC. Usefulness of the Audit of Diabetes-Dependent Quality-of-Life (ADDQoL) questionnaire in patients with diabetes in a multi-ethnic Asian country. Pharmacoeconomics 24: 673-682, 2006.

10. Sundaram M, Kavookjian J, Patrick JH, Miller LA, Madhavan SS, Scott VG. Quality of life, health status and clinical outcomes in Type 2 diabetes patients. Qual Life Res 16: 165-177, 2007.

11. Kong D, Ding Y, Zuo X, et al. Adaptation of the Audit of Diabetes-Dependent Quality of Life questionnaire to people with diabetes in China. Diabetes Res Clin Pract 94: 45-52, 2011.

12. Nunnally JC, Bernstein IH. Psychometric theory. 3rd ed. McGrawHill, New York, 1994: 752.

13. Lustman PJ, Clouse RE, Griffith LS, Carney RM, Freedland KE. Screening for depression in diabetes using the Beck Depression Inventory. Psychosom Med 59: 24-31, 1997.

14. National Kidney Foundation. K/DOQI clinical practice guidelines for chronic kidney disease: evaluation, classification, and stratification. Am J Kidney Dis 39: S1-S266, 2002.

15. Isomaa $B$, Almgren $P$, Henricsson $M$, et al. Chronic complications in patients with slowly progressing autoimmune type 1 diabetes (LADA). Diabetes Care 22: 1347-1353, 1999.

16. Ali S, Stone MA, Peters JL, Davies MJ, Khunti K. The prevalence of co-morbid depression in adults with Type 2 diabetes: a systematic review and meta-analysis. Diabet Med 23: 1165-1173, 2006.

17. Lin EH, Katon W, Von Korff M, et al. Relationship of depression and diabetes self-care, medication adherence, and preventive care. Diabetes Care 27: 2154-2160, 2004.

18. Lemon SC, Rosal MC, Welch G. Measuring quality of life in lowincome, Spanish-speaking Puerto Ricans with type 2 diabetes residing in the mainland U.S. Qual Life Res 20: 1507-1511, 2011.

19. Collins MM, O'Sullivan T, Harkins V, Perry IJ. Quality of life and quality of care in patients with diabetes experiencing different models of care. Diabetes Care 32: 603-605, 2009.

20. Klein BE, Klein R, Moss SE, Cruickshanks KJ. Parental history of diabetes in a population-based study. Diabetes Care 19: 827830, 1996.

21. Akinci F, Yildirim A, Gozu H, Sargin H, Orbay E, Sargin M. Assessment of health-related quality of life (HRQoL) of patients with type 2 diabetes in Turkey. Diabetes Res Clin Pract 79: 117-123, 2008.

22. Trief PM, Grant W, Elbert K, Weinstock RS. Family environment, glycemic control, and the psychosocial adaptation of adults with diabetes. Diabetes Care 21: 241-245, 1998.

23. UK Prospective Diabetes Study (UKPDS) Group. Intensive bloodglucose control with sulphonylureas or insulin compared with conventional treatment and risk of complications in patients with type 2 diabetes (UKPDS 33). Lancet 352: 837-853, 1998.

24. Bashoff EC, Beaser RS. Insulin therapy and the reluctant patient. Overcoming obstacles to success. Postgrad Med 97: 86-90, 93-96, 1995.

(C) 2013 The Japanese Society of Internal Medicine

http://www.naika.or.jp/imonline/index.html 